\title{
Viljelytekniikan vaikutus viljan punahomeisiin ja toksiineihin
}

Päivi Parikka ${ }_{1)}$, Veli Hietaniemi 2 ), Sari Rämö 2 ) ja Heikki Jalli ${ }_{1)}$ ${ }_{1)}$ MTT kasvintuotannon tutkimus, 31600 Jokioinen, paivi.parikka@mtt.fi, heikki.jalli@mtt.fi 2)MTT palveluyksikkö, laboratoriot, 31600 Jokioinen, veli.hietaniemi@mtt.fi, sari.ramo@mtt.fi

Peltokasvien viljelytekniikka on viime vuosina muuttunut suorakylvön lisääntyessä ja yksipuolisen viljanviljelyn lisääntyessä. Hometoksiinien lisääntymisestä viljasadoissa on saatu viitteitä. Viljelytekniikan muutosten vaikutusta punahomeisiin ei ole aikaisemmin meillä tutkittu.

Maanmuokkauksen ja kasvitautitorjunnan vaikutusta kauran ja ohran Fusarium- tartuntaan ja sadon mykotoksiinipitoisuuksiin tutkittiin kenttäkokeessa Jokioisilla 2003-2006. Kentällä verrattiin kyntöalustaan perustetun ja suorakylvetyn viljan Fusarium-tartuntaa tähkälletulosta valmiiseen satoon asti. Mykotoksiinit määritettiin sekä lajittelemattomasta että lajitellusta sadosta sekä kehittyvistä jyvistä kahdesta neljään viikkoa ennen sadonkorjuuta. Tutkimuksessa oli mukana neljä elintarvikekaura- ja neljä mallasohralajiketta.

Fusarium-sieniä todettiin viljasta aina sen tähkälle tulosta puintiin asti. Tartuntaan vaikuttavat kasvukauden sääolot, kasvinjäte kasvualustassa ja viljalaji sekä lajike. Ensimmäiset tartunnat voidaan havaita erityisesti kauralla jo röyhyn tullessa esiin, jolloin Fusarium langsethiae -laji on jo todettavissa kukista. Laji tartuttaa myös ohraa jo tähkälletulovaiheessa. Fusarium-lajien määrä lisääntyy kasvun edistyessä ja viimeiset tartunnat tapahtuvat jyvien pintaan puintivalmiissa sadossa. Viimeisinä tartuttavat ja lisääntyvät $F$. culmorum ja $F$. avenaceum. Ennen korjuuta oli havaittavissa sekä deoksinivalenoli (DON)-, nivalenoli (NIV)- että T2/HT- pitoisuuksia, jotka kasvoivat edelleen viljan valmistuessa. Sekä Fusarium-tartuntaan että mykotoksiinipitoisuuksiin vaikuttivat sääolot että muokkaus. Kasvitautitorjunnan vaikutus vaihteli. Kosteassa viihtyvät F. culmorum, F. graminearum olivat runsaita kasvukausina 2004 ja 2005 ja niiden muodostamaa deoksinivalenolia havaittiin silloin eniten. T2/HT-2muodostajat $F$. langsethiae ja $F$. sporotrichioides viihtyvät myös kuivassa ja lämpimässä ja toksiinipitoisuudet olivat korkeimmat kauroilla. Suorakylvö lisää kasvinjätteessä hyvin säilyvän $F$. avenaceumlajin määrää sadossa. Samoin F. langsethiae hyötyi muokkaamattomuudesta erityisesti kuivana kesänä 2006 ja kohotti toksiinipitoisuuksia.

Muokkauksella ei ollut suurta vaikutusta sadon DON- pitoisuu- teen, eikä suorakylvö näyttänyt sen osalta olevan riski sadon laadulle. Toisaalta Fusarium-tartunnan lisääntyminen suorakylvössä voi vaikuttaa heikentävästi mallasohran käyttökelpoisuuteen. Suorakylvö voi myös olla riski kauralle T2/HT-2 -toksiinien pitoisuuden noustessa jopa merkittävästi.

Fusarium-tartunta heikentää jyvien kehitystä ja pienissä jyvissä myös toksiinpitoisuus on korkein. Sadon lajittelulla voidaan alentaa toksiinipitoisuutta, jopa määritysrajalle.Vaikutus oli selvin T2/ HT-2- toksiinien pitoisuudessa, hieman vähäisempi DON pitoisuudessa.

Asiasanat: Fusarium-sienet, muokkaus, suorakylvö, fungisidikäsittely, trikotekeenit 


\section{Johdanto}

Viljanviljelyn tekniikka on muuttunut nopeasti viime vuosina. Tilojen viljelyalojen kasvu on johtanut tarpeeseen nopeuttaa viljelytyötä. Taloudellisuutta ja työn säästöä tavoiteltaessa suorakylvö on vallannut nopeasti alaa. Menetelmän yleistymiseen ovat vaikuttaneet myös ympäristönäkökohdat. Myös sänkimuokkausta käytetään entistä enemmän. Suorakylvössä olkijäte ja sänki jää maan pintaan, sänsänkimuokkaus kultivaattorilla sekoittaa jätettä jonkin verran maahan. Vähennetyn muokkauksen vaikutuksesta viljan Fusarium-tartuntaan ja mykotoksiinien esiintymiseen on 1990-luvun lopulta lähtien julkaistu tutkimustuloksia Keski-Euroopasta, mm Sveitsistä ja Iso-Britanniasta sekä pohjoismaista Norjasta. Maan muokkauksen vähentyessä ja viljeltäessä muokkaamatta maan pintaan jää kasvinjätettä, jossa myös kasvitautien aiheuttajat, kuten lehtilaikkutautisienet ja Fusarium-lajit säilyvät (Bailey \& Duczek 1996, Yi et al, 2001). Kynnön poisjättämisen on havaittu vaikuttavan myös toksiiniriskiin erityisesti sateisilla alueilla. Norjassa on saatu viitteitä vähennetyn muokkauksen Fusariumsaastuntaa ja toksiineja lisäävästä vaikutuksesta, samoin Saksassa (Henriksen 1999, Yi et al., 2001). Myös fungisidien käytön on todettu aiheuttavan ongelmia, erityisesti laajavaikutteisen atsoksistrobiinin on todettu lisäävän toksiiniriskiä. Aineen käyttö suosii varsinkin toksiineja muodostavaa Fusarium culmorum -sientä (Simpson et al., 2001, Jennings \& Turner 2000). Toisaalta on todettu onnistuneen torjunnan Fusarium -sieniin vaikuttavalla valmisteella parantavan satoa, vähentävän sienisaastuntaa ja deoksinivalenolipitoisuutta viljassa (Homdork et al., 2000a).

Fusarium-lajeja on selvitetty suomalaisesta viljasta useaan otteeseen 1970-luvulta lähtien, jolloin esiintyi runsaasti niiden muodostamia mykotoksiineja. Toksiinitietoja ja Fusarium- sienten esiintymistä on harvoin yhdistetty toisiinsa. Meillä ja muissa Pohjoismaissa vallitsevana lajina on $F$. avenaceum, joka ei ole yleisemmin esiintyvän deoksinivalenolin (DON) tuottaja. Lajia esiintyy erityisen runsaana sateisina ja viileinä kesinä, kuten 1998 (Eskola et al., 2001, Henriksen 1999). Toisaalta korkeat lämpötilat kasvukaudella suosivat merkittäviä toksiininmuodostajia, erityisesti F. culmorum ja F. graminearum ovat tärkeitä lämpimässä (Bottalico \& Perrone, 2002). Sadonkorjuun myöhästyminen lisää Fusarium- sienten kasvua ja siten toksiiniriskiä kosteuden lisääntyessä. Fusarium- sienet muodostavat toksiineja viljaan kasvukaudella. Lämminilmakuivatussa viljassa sienet säilyvät, mutta kuivassa varastoituna haitallisia yhdisteitä ei enää muodostu (Homdork et al., 2000b). Kauraa on pidetty viljalajeista altteimpana Fusarium-tartunnalle, mutta norjalaisten tutkimusten mukaan ohralla tartuntaa esiintyy yhtä usein (Langseth \& Elen 1996). Myös viljalajikkeiden välillä on eroja sienitartunnassa (Langseth \& Elen 1997, Jennings \& Turner 2000, Henriksen 1999).

Muokkauksen ja suorakylvön vaikutusta viljan Fusarium-tartuntaan ja toksiinipitoisuuteen ei ole aikaisemmin tutkittu Suomessa. Mykotoksiinien raja-arvojen asettaminen Euroopan Unionin alueelle loi erityisesti tarpeen tarkastella viljelytekniikan vaikutusta viljan toksiineihin ja mahdollisuuksiin pitää toksiinitaso alhaisena. Tutkimuksen tavoitteena oli selvittää, onko suorakylvö riski kauran ja ohran laadulle ja miten lippulehtiasteella tehty kasvitautitorjunta vaikuttaa viljan Fusarium-tartuntaan ja toksiinipitoisuuteen.

\section{Aineisto ja menetelmät}

\section{Kokeen perustaminen ja lajikkeet}

Kyntöä ja suorakylvöä vertailtiin 2004-2006 kenttäkokeessa, joka perustettiin Jokioisille. Koealueen maalaji on hietasavi. Kyntämättömälle koelohkolle oli 2002 syksyllä kynnetty kaistat muokkausruutuja varten, loppu alue jätettiin kyntämättä. Alustava koe tehtiin 2003 kaura- ja ohralajikkeilla ja sitä jatkettiin 2004 alkaen neljällä elintarvikekaura- ja neljä mallasohralajikeella. Kauralajikkeina olivat 'Roope', 'Freja', 'Veli' ja 'Belinda' ja ohralajikkeina 'Saana', 'Scarlett', 'Barke' ja 'Annabell'.

Vuoden 2004 kokeella oli kaikille koejäsenille esikasvina kaura, myöhemmin ruudut sijoitettiin alueelle niin, että ohraruutujen esikasviksi tuli kaura ja kauraruutujen esikasviksi ohra. Kylvösiemen peitattiin Täyssato S- valmisteella (karboksiini+imatsaliili). Ruudun koko oli 15 x 3 m ja kerranteita oli kuusi. Koealueella suojaruudut ja käytävät oli kylvetty kauralle ('Veli'). Koeruudut kylvettiin peltokäyttöön tarkoitetuilla koneilla, suorakylvökone Vieskan Metalli, kyntöalueilla Tume 2500 kylvö- 
lannoitin. Lannoituksen N-määrä mitoitettiin ympäristötuen ehtojen mukaisesti, lannoitteena Y-lannos 3 (NPK 20-3-8).

\section{Kasvinsuojelu}

Rikkakasvien torjuntaan koko alueelle käytettiin Ariane S 2 1/ha ja kasvunsääde Moddus $(0,2$ 1/ha) annettiin yhdessä tai kahdessa erässä. Kasvitautitorjuntakäsittely Sportak 45 HF 1 1/ha tehtiin tautitorjuntaruuduille lippulehtiasteella. Juolavehnää torjuttiin syksyllä 2004 suorakylvöruuduilta glyfosaatilla (Glyfonova 31/ha + kiinnite) ja pesäkkeistä syksyllä 2005 (Rambo 31/ha +BF kiinnite)

\section{Näytteenotto ja havainnot}

Tähkä- ja röyhynäytteiden otto Fusarium-tartunnan määritystä varten aloitettiin välittömästi viljan tullessa tähkälle tai röyhylle (2004 viikolla 29 kyntöruuduilla, viikolla 30 suorakylvöruuduilla, 20052006 viikolla 27 sekä kyntö- että suorakylvöruuduilla).Näytteitä kerättiin joka ruudulta joka toinen viikko (20 kasvia/ruutu, jokaisesta kasvista 2 tähkylää määritykseen) ja joka toinen viikko kerättiin koejäsenittäin kokonaisnäyte (60 kasvia).Fusarium- määritykset tehtiin myös tuoreesta, puidusta viljasta sekä kuivatusta, lajitellusta ja lajittelemattomasta sadosta.

Toksiinimäärityksiä varten kerättiin 2005-2006 kasvustonäytteet, kokonaisnäyte/koejäsen, 2005 kyntöruuduilta 9.8 ja suorakylvöstä 16.8., vuonna 2006 näytteet kerättiin kaikilta ruuduilta viikolla viikolla 30 (heinäkuun loppu).Toksiinit määritettiin sekä kuivatusta lajittelemattomasta että lajitellusta sadosta.

Puitu sato kuivattiin säkkikuivurissa. Lajittelussa käytettiin alaseula $1,5 \mathrm{~mm}$ alaseula ja $4 \mathrm{~mm}$ yläseula). Lajittelujätteestä otettiin näytteet toksiinimäärityksiä varten 2005 ja 2006.

\section{Fusarium- ja toksiinimääritykset}

Fusarium-sienten eritystä varten tähkylöitä ja jyviä viljeltiin viljeltiin jyvistä PCNB-alustalla (Nash \& Snyder medium, Nelson et al, 1983) huoneenlämmössä $\left(22^{\circ} \mathrm{C}\right)$ ja saadut kasvustot siirrostettiin määritystä varten perunadekstroosi alustalle (PDA) alustalle määritystä varten. Fusarium-lajit määritettiin viljelmistä mikroskoopilla.

Näytteistä määritettiin trikotekeentoksiinit deoksinivalenoli (DON), diasetyyliscirpenoli (DAS), 3-asetyylideoiksinivalenoli (3-Ac-DON), fusarenon-X (F-X), nivalenoli (NIV), T-2 ja HT-2 sekä 15asetyylideoksinivalenoli (15-AcDON) analysoitiin ja mitattiin jauhetuista viljanäytteistä stardardimenetelmin kaasukromatografi-massaspektrometrillä (GC-MS9 (Pettersson \& Langseth, 2002). Zearalenonin määritykseen HPLC-laitetta (Romer Labs Methods: Zearalenone HPLC MycoSep ${ }^{\mathrm{TM}} 226$ Method). Pienin määritettävissä oleva pitoisuus $25 \mathrm{ug} / \mathrm{kg}$

\section{Tulokset ja tulosten tarkastelu}

Fusarium-sienet tartuttavat viljaa aina sen tähkälle tulosta puintiin asti. Ensimmäiset tartunnat havaittiin kauralla jo röyhyn tullessa esiin, jolloin Fusarium langsethiae -laji oli jo todettavissa kukista jokaisena koevuotena (Kuva 1.). Laji tartuttaa myös ohraa jo tähkälletulovaiheessa, mutta se oli aineistossa yleisempi kauralla kuin ohralla. F. langsethiae on lajina varsin uusi (Torp \& Nirenberg 2004) ja sitä pidetään Norjassa tärkeimpänä trikotekeenitoksiinien tuottajana (Kosiak et al 2003). Toinen aikainen tartuttaja on F. poae, joka oli myös runsaampi kauralla kuin ohralla. Laji havaittiin aikaisin tähkissä ja röyhyissä myös kuivana ja lämpimänä kesänä 2003 (Parikka et al 2005). Viljalajikkeiden välillä oli eroja tartunnan aikaisuudessa ja määrässä.

Viljelytekniikka vaikutti myös tartunnan yleisyyteen. Vuonna 2004 F. langsethiae oli runsaampi kyntöruuduilla kuin suorakylvössä, 2005 se oli jonkin verran yleisempi suorakylvössä. Vuonna 2006 laji oli selvästi yleisempi suorakylvönä kylvetyissä kasvustoissa aina valmiiseen satoon asti (Kuva 2.) Toisaalta F. poae oli ensin yleisempi suorakylvössä, mutta 2005 ja 2006 tilanne oli päinvastainen, laji oli runsaampi kyntöruuduilla. Fusarium-lajien määrä lisääntyi kasvun edistyessä ja viimeiset tartunnat tapahtuivat jyvien pintaan puintivalmiissa sadossa. Viimeisinä tartuttivat ja lisääntyivät $F$. culmorum ja $F$. avenaceum. Lajeista $F$. avenaceum on tavallisesti yleisin viljasadon Fusarium-laji, erityisesti kosteassa ja viileässä (Eskola et al., 2001). Saatujen tulosten mukaan F. langsethiae ja $F$. poae voivat olla runsaita sekä kuivina että kosteina kesinä. F. culmorum ja $F$. avenaceum vaativat kosteutta tartuttaakseen ja niitä oli varsin vähän kesän 2006 sadossa, mutta 2004 ja 2005 ne olivat runsaita sekä ohral- 
la että kauralla. Kuivana kesänä lajit alkoivat yleistyä vasta elokuun puolivälissä sateiden jälkeen. Siksi niitä tavattiin runsaimmin myöhäisillä lajikkeilla. F. culmorum ja $F$. graminearum viihtyvät lämpimässä (Xu, 2003), siksi niitä oli 2005 varsin runsaasti, toisaalta lämpimänä kesänä 2006 kuivuus esti tartuntaa.

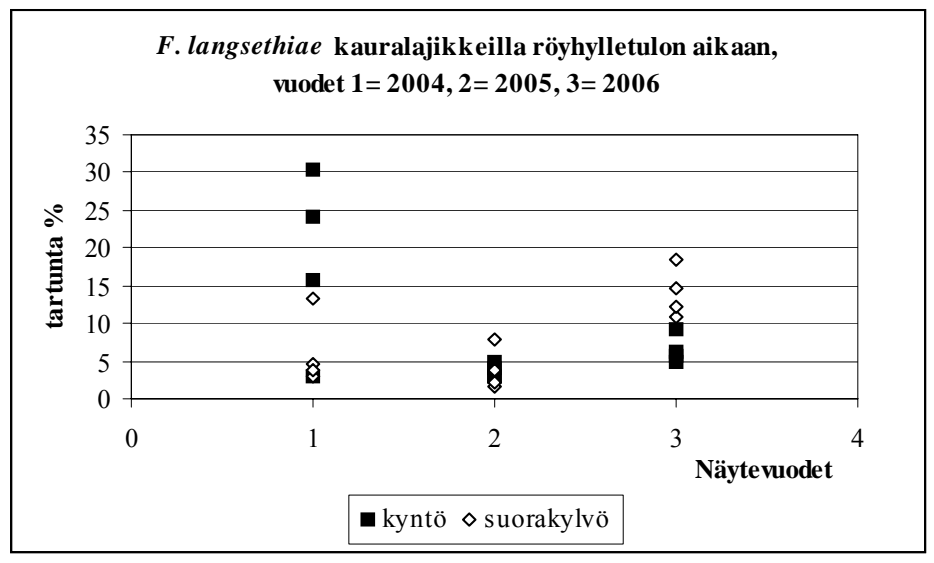

Kuva 1. Fusarium langsethiae eristettiin kauran röyhylle tulon aikaan, heinäkuun alkupuolella kaikkien kokeessa olleiden kauralajikkeiden röyhyistä sekä kyntö- että suorakylvöruuduilta.

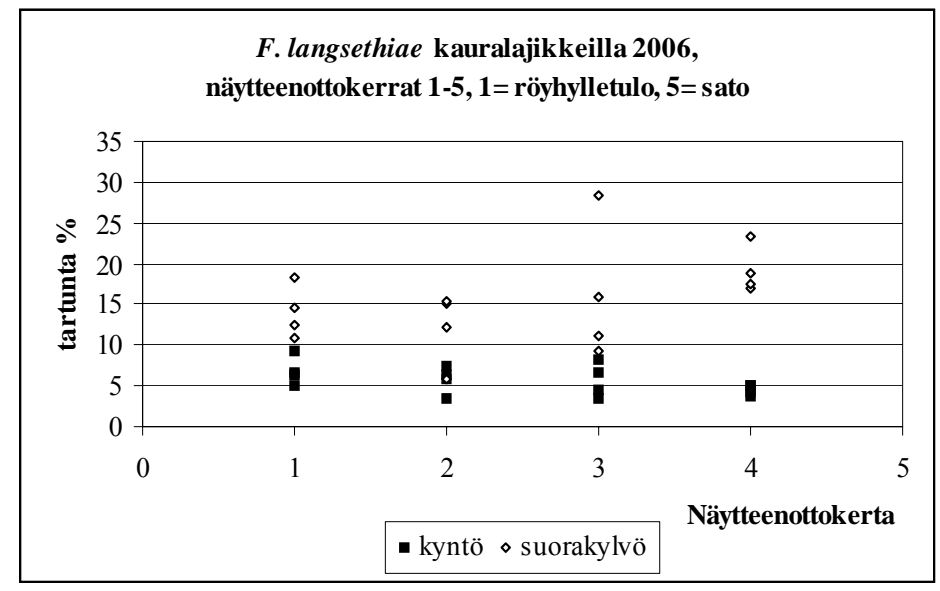

Kuva 2. Fusarium langsethiae oli vuonna 2006 yleisin suorakylvetyssä kaurassa aina röyhylle tulosta satoon asti.

Vuosina 2004 ja 2005 sadosta määritettiin F. langsethiae-tartuntaa vähän, ohralla ei juuri lainkaan. Lajin esiintyminen tutkituissa näytteissä väheni viljan valmistumisen lähestyessä. Muut Fusarium-lajit sen sijaan runsastuivat kasvukauden edetessä ja loppukesän kosteus lisäsi tartuntaa nopeasti. $F$. avenaceum oli runsain suorakylvettyjen viljojen sadossa. F. culmorum puolestaan oli yleisin kyntöruutujen viljassa, erityisesti ohralajikkeilla (Kuva 3.), joista 'Barke' ja 'Scarlett' olivat altteimpia tartunnalle. F. poae runsastui nopeasti loppukesällä ja oli yleinen kauralla 2005 kuten myös kuivana vuonna 2006 (Kuva 4.). Kuivana kesänä 2006 F. langsethiae ei vähentynyt viljan valmistuessa, vaan laji oli jopa yleisin aikaisin korjatussa sadossa Roope- ja Veli-lajikkeilla. Runsain se oli kauralajikkeista myöhäisimmillä Belinda- ja Freja-lajikkeilla. Samalla kosteassa viihtyviä Fusarium-lajeja esiintyi niukasti ja tartuntaa esiintyi vain myöhäisimmillä lajikkeilla. Mykotoksiineja määritettiin kehittyvistä jyvistä kaksi-neljä viikkoa ennen sadonkorjuuta ja puidusta sadosta. Ennen korjuuta oli havaittavissa sekä deoksinivalenoli (DON), nivalenoli (NIV) että T2/HT-2 pitoisuuksia jotka kasvoivat edelleen viljan valmistuessa. Sekä Fusarium- tartuntaan että mykotoksiinien määrään vaikuttivat sääolot että muokkaus. Kasvitautitorjunnan vaikutus vaihteli. Kosteassa viihtyvät $F$. culmorum ja F. graminearum olivat runsaita kasvukausina 2004 ja 2005 ja niiden muodostamaa deoksinivalenolia havaittiin silloin 
eniten. Korkein DON pitoisuus, $800 \mu \mathrm{g} / \mathrm{kg}$, mitattiin Barke-lajikkeella. T2/HT-2 muodostajat $F$. langsethiae ja $F$. sporotrichioides (Tharane et al 2004) viihtyvät kuivassa ja lämpimässä. Korkeimmat toksiinipitoisuudet määritettiin kauroilta. Nivalenolia muodostava F. poae (Thrane et al, 2004) oli runsain 2005, mutta myös 2006 lajia oli runsaasti. Korkeimmat NIV pitoisuudet mitattiin Saanalajikkeella.

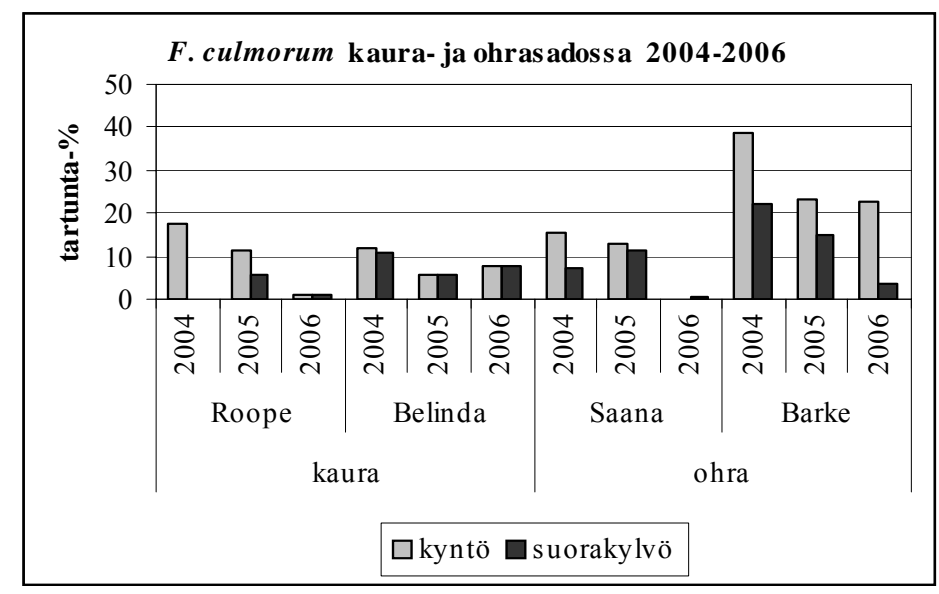

Kuva 3. Fusarium culmorum oli runsain kyntöalustaan perustetussa ohrakasvustossa, lajikkeiden välillä oli kuitenkin huomattavia eroja tartunnassa.

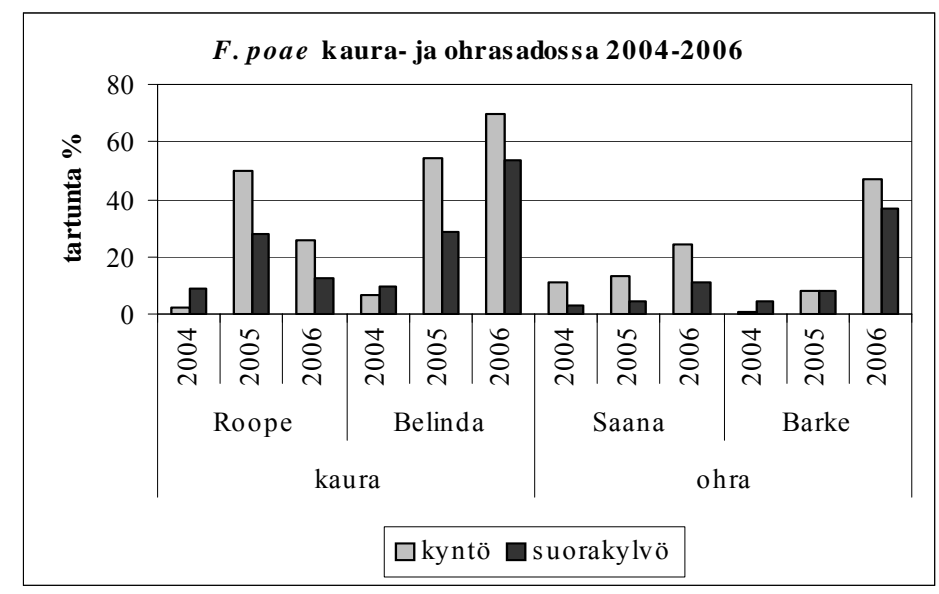

Kuva 4. Fusarium poae oli kauralla yleisempi kuin ohralla, mutta lajikkeiden välillä oli huomattavia eroja tartunnan määrässä.

Suorakylvö lisäsi kasvinjätteessä hyvin säilyvän F. avenaceum-lajin määrää sadossa. Samoin F. langsethiae hyötyi muokkaamattomuudesta erityisesti kuivana kesänä 2006 ja kohotti toksiinipitoisuuksia. Muokkauksella ei ollut suurta vaikutusta sadon DON-pitoisuuteen. Suorakylvössä DON-pitoisuudet olivat alempia kuin kyntöruutujen sadossa, eikä suorakylvö näyttänyt sen osalta olevan riski sadon laadulle. Toisaalta Fusarium-tartunnan lisääntyminen suorakylvössä voi vaikuttaa heikentävästi mallasohran käyttökelpoisuuteen. Langseth \& Elen (1996) ovat todenneet, ettei kauran ja ohran DONpitoisuuksissa ole eroja, jos ne on viljelty samanlaissa oloissa. Nyt viljat olivat samalla lohkolla ja havaitut toksiinipitoisuudet olivat varsin samantasoisia ja havaittujen erojen syynä oli joko lajike tai viljelymenetelmä. Suorakylvö voi myös olla riski kauralle T2/HT-2 toksiinipitoisuuden noustessa jopa yli Euroopan Yhteisön komission marraskuussa 2007 esittämän enimmäispitoisuuden $500 \mu \mathrm{g} / \mathrm{kg}$.

Kasvitautitorjunnalla ei näyttänyt olevan kovin merkittävää vaikutusta Fusarium- tartuntaan ja toksiinipitoisuuteen. Ohralla saattoi kuitenkin havaita jonkin verran vaikutusta hometartuntaan. Sadon lajittelu vähensi mykotoksiinipitoisuuksia, eniten se vähensi T2/HT-2 pitoisuutta, mutta myös DONmäärät lajitellussa sadossa olivat lajittelematonta alhaisempia. 


\section{Johtopäätökset}

Tartuntaan vaikuttavat kasvukauden sääolot, kasvinjäte kasvualustassa ja viljalaji sekä lajike. Yksipuolinen viljakierto lisää toksiininmuodostajien mahdollisuutta lisääntyä kasvukaudesta toiseen. Kasvitautitorjunta ei tulosten perusteella suojaa riittävästi punahometartunnalta ja toksiinien muodostumiselta. Fusarium-tartunta heikentää jyvien kehitystä ja pienissä jyvissä myös toksiinpitoisuus on korkein. Sadon lajittelulla voidaan alentaa toksiinipitoisuutta, jopa määritysrajalle. Suorakylvö on riski kauranviljelyssä, sillä erityisesti lämpiminä vuosina T2/HT-2 toksiinien muodostajat tartuttavat suorakylvettyä kauraa voimakkaimmin ja toksiineja löytyy sadosta eniten. Viljalajien ja lajikkeiden välillä on kuitenkin eroja, yleensä myöhäiset lajikkeet ovat alttiimpia punahometartunnalle ja niillä esiintyy myös runsaimmin toksiineja. Tiedämme kuitenkin liian vähän lajikkeiden taudinalttiudesta, jotta lajikesuosituksia voisi antaa. Viime kädessä suurin vaikutus punahomeisiin on kasvukauden säällä: sateet suosivat hometartuntaa ja lisäävät toksiiniriskiä korjuun myöhästyessä.

\section{Kirjallisuus}

Bailey, K.L.\& Duczek, J.L. 1996. Managing cereal diseases under reduced tillage. Canadian Journal of Plant Pathology 18:159-167.

Bottalico, A. \& Perrone, G. 2002. Toxigenic Fusarium species and mycotoxins associated with head blight in small- cereals in Europe. European Journal of Plant Pathology 108:611-624.

Eskola, M., Parikka, P.\& Rizzo, A. 2001. Trichothecenes, ochratoxin A and zearalenone

contamination and Fusarium infection in Finnish cereal samples in 1998. Food Additives and Contaminants 18, 8/2001:707-718.

Henriksen, B.1999. Factors affecting Fusarium infection and mycotoxin contents in cereal grains. Dissertation 98 pp. Agricultural University of Norway.

Kosiak, B., Torp, M., Skjerve, E. \& Thrane, U. 2003. The prevalence and distribution of Fusarium species in Norwegian cereals: a survey. Acta Agriculturae Scandinavica, Section B, Soil and Plant Science 53:168-176.

Langseth, W. \& Elen, O. 1996. Differences between barley, oats and wheat in the occurrence of deoxynivalenol and other trichothecenes in Norwegian grain. Journal of Phytopathology 144:113-118.

Nelson, P.E., Toussoun, T.A. \& Marasas, W.F. O. 1983. Fusarium Species: An Illustrated Manual for Identification. Pennsylvania State University Press, University Park.

Parikka, P., Hietaniemi, V. \& Rämö, S. 2005. The effect of tillage on Fusarium infection and mycotoxins on barley and oats. The BCPC international congress Crop science \& technology 2005 : Congress proceedings, volume 1, SECC, Glasgow, Scotland, UK, 31 Oct - 2 Nov 2005. Glasgow: BCPC. p. 423-428.

Pettersson, H. \& Langseth, W. 2002. Intercomparison of Trichothecene Analysis and Feasibility to Produce Certified Calibrants and Reference Material: Method Studies, European Commission, EUR20285/1 EN, 2002

Thrane, U., Adler, A.,Clasen, P.-E., Galvano, F., Langseth, W., Lew, H., Logrieco, A., Nielsen, K. F.\& Ritieni, A. 2004. Diversity in metabolite production by Fusarium langsethiae, Fusarium poae and Fusarium sporotrichioides. International Journal of Food Microbiology 95:257-266.

Torp, M. \& Nirenberg, H. I. 2004 Fusarium langsethiae sp.nov. on cereals in Europe. International Journal of Food Microbiology 95:247-256.

Yi, C., Kaul, H.P., Kubler, E., Schwadorf, K. \& Aufhammer, W. 2001. Head bligth (Fusarium graminearum) and deoxynivalenol concentration in winter wheat as affected by pre-crop, soil tillage and nitrogen fertilization. Zeitschrift für Pflanzenkrankheiten und Pflanzenschutz 108 (3):217-230.

Xu, X. 2003. Effects of environmental conditions on the development of Fusarium ear blight. European Journal of Plant Pathology 109:683-689. 